https://doi.org/10.48009/2_iis_2005_29-35

\title{
DECISION SUPPORT SYSTEMS ANALYSIS WITH SIMULATION
}

\author{
Shamsuddin Ahmed, BCB, KIMEP, Kazakhstan, Dr_Shamsuddin_Ahmed@Yahoo.Com \\ Jim Cross, Edith Cowan University, Perth, Australia
}

\begin{abstract}
A decision support system (DSS) is developed for car registration in a Gulf Cooperation Council $(G C C)$ country using simulation model. The car registration is managed by a government organization but a private corporation certifies the car fitness. High variation is noticed in registration and therefore a simulation model is developed to evaluate the registration operations and policies. The simulation model replicates the existing operational policies and evaluates feasible policies to maximize system performance. The suggested DSS model provides robust analysis in system time, service time and average queue lengths as an index to monitor the service quality.
\end{abstract}

Key Words: Decision Support System (DSS), Simulation, Car Registration, Service Operation, Systems Analysis, Information Maximization

\section{INTRODUCTION}

A visual SLAM [1] computer simulation model is developed to analyze car registration and inspection in a GCC country. Founded on 26 May 1981, the GCC countries consist of Bahrain, Qatar, Saudi Arabia, Kuwait, United Arab Emirates, and Oman. The aim of the GCC countries is to promote coordination between member states in all fields in order to achieve unity.

A series of interview are planned with the managers, engineers and workers at the car inspection stations to identify the steps a customer should follow to do the car registration, as shown in Figure 1. The pressing problem is the long waiting time for the customer at the car registration station. Figures 2 and 3 display the snapshot of the car arrival pattern. The car arrival is random. A variety of registration and renewal jobs exist depending on the status of the test, nationality of the person and time of the day. Customers demand high quality, customized services with fast response time [2]. The simulation model provides competitive strategy [1] and consequently improves organizational performance [3, 4]. A multivariate information maximization model is built from simulation results. The DSS model developed thus provides information about the system efficiency [5,6]. The DSS model points to the critical factors for system improvements.

\section{Data Collection}

The necessary data is collected with a fact-finding technique [7]. In this approach, interviews, observations, sampling techniques and the existing documentation (including memos and data base) are used to collect information. The time between arrivals of cars is shown in Figures 2(b) and 3(b); which suggests that the service time and system time are stochastic in nature. 


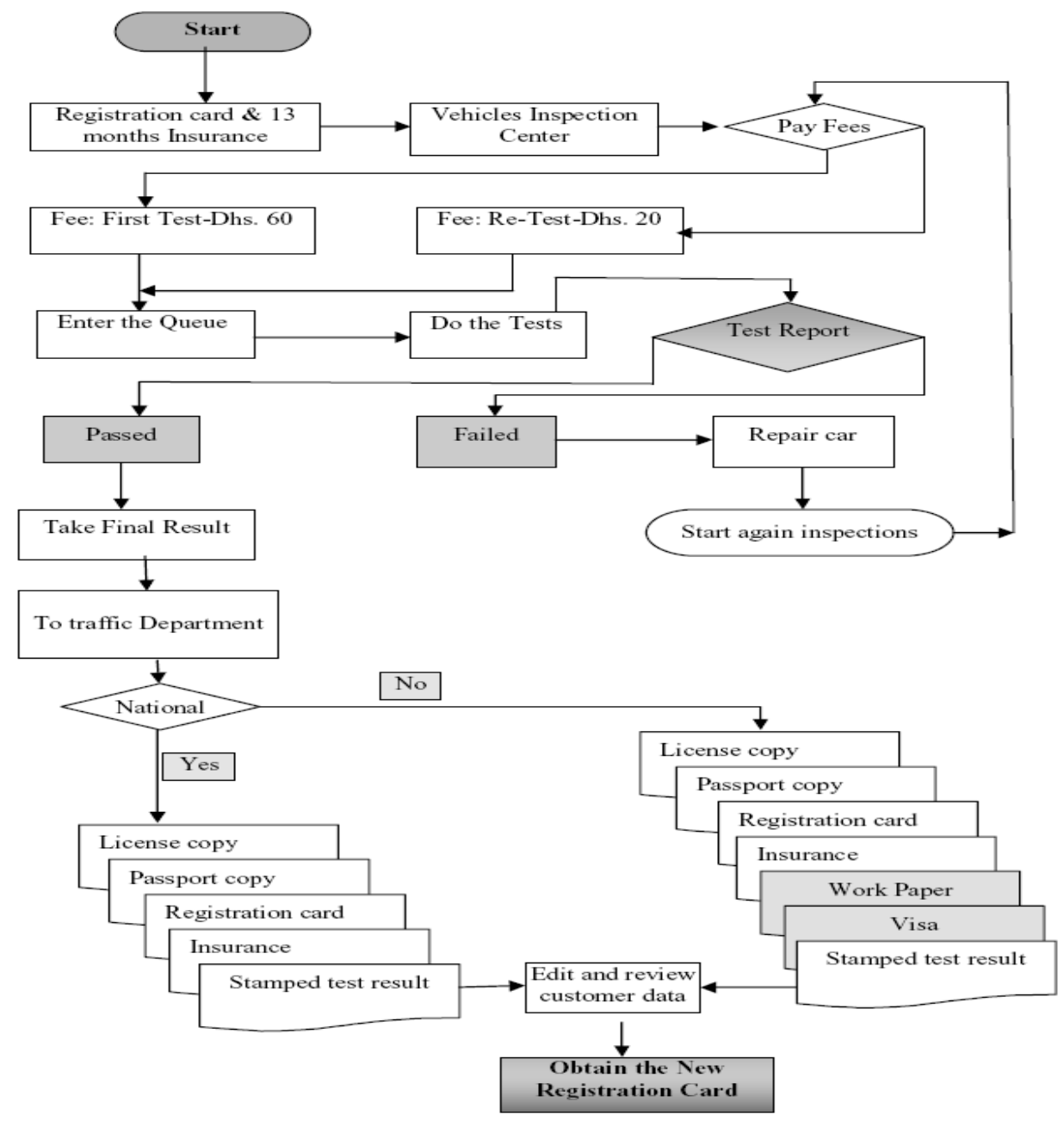

Figure 1: Flowchart Illustrating Renewal and Registration of Car

\section{SIMULATION MODELING AND METHOD ANALYSIS}

In a simulation model the cars move through a series of testing stations such as hydrocarbon, tires, rims, break system, shock absorber, visual, body and chassis in the inspection process. Figure 4 is the AweSim network simulation model. At the end of the inspection, the result is either pass or fail. If the final result is fault free, the car is routed to the traffic department to finish the renewal of the registration card. Otherwise, the result is fail if the car functions improperly. Hence, the car is routed to the repair center to fix the defects identified. After being repaired, the car is again sent back to the inspection center to obtain a pass certificate if it satisfies the test requirements. The car registration system is shown in Figure 1, while Figures 2(a) and 3(a) are the service and system time information.

The car arrives at the registration center and is routed to the inspection station according to Figure 1. The three independent lanes for testing in the inspection station are represented as servers [8]. If the three testing lanes are busy, three parallel queues of cars are formed. This process can be conveniently modeled in AweSim with three QUEUE nodes that precede the service activity as testing, which represents three independent SERVERS. The service activity is denoted by the inspectors and 80 percent of the cars passed the test and depart to the traffic 
department. The remaining 20 percent of the cars inspected failed the inspection test. Hence, repair is recommended. The repair is modeled with a QUEUE node followed by a service activity with a capacity of 15 cars. Following the adjustment operation, the car is routed back to the inspection area of QUEUE with a first in first out (FIFO) criteria.
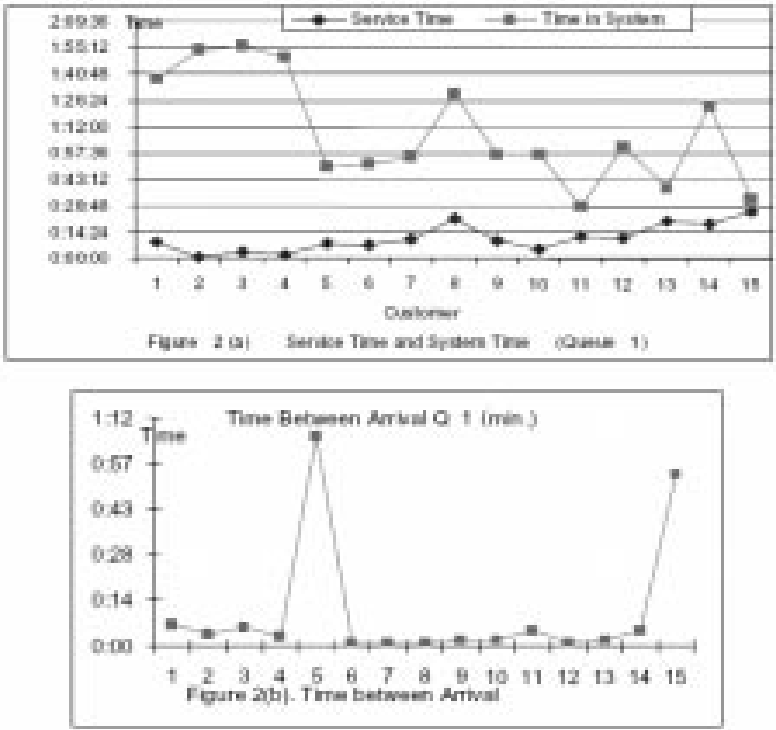
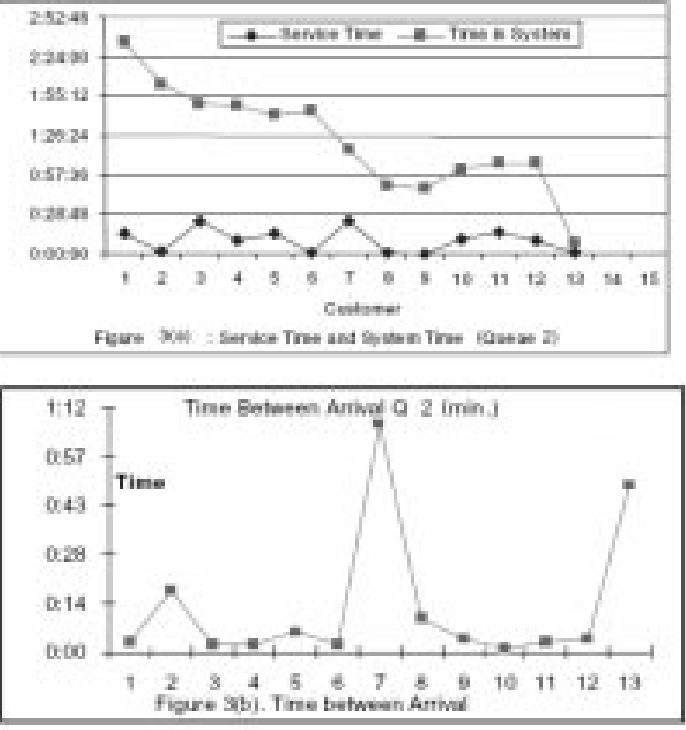

The AweSim graphical model is shown in Figure 4. Entities representing cars are created by the CREATE node with the time between entities uniformly distributed between 10 and 25 minutes. Each car advances to one of the QUEUE nodes. The QUEUE node with the least number of cars proceeds directly to service for inspection. The inspection lane is represented by the three emanating SERVICE activities following the queue. The service time for all the servers is identified as uniform distribution in the range between 25 and 35 minutes.

After inspection the car arrives at a GOON node where it is probabilistically routed. One activity leads to the COLECT node, representing departure from the traffic department; the other activity leads to the $Q U E U E$ node, representing the waiting line for the repairing activity. Entities, which are routed to the COLCT node, have interval statistics collected based on the time of creation. The information is stored in ATRIB [1] that is assigned at the CREATE node. The total time a car spends in the inspection and repairing areas are recorded. The cars are then removed from the model with the TERMINATE node. The CONTROL statement runs the simulation model.

\section{SIMULATION EXPERIMENT SETTING}

The simulation summary report is collected in Table 2. The report contains interval statistics on the TIME IN SYSTEM acquired from the COLCT node. The length of simulation run is 6000 minutes and is controlled with the INITILIZE statement. A high variability in system times for car registration is evident from the minimum and maximum times recorded in report. A high value of standard deviation in the system suggests that some of the cars can't be repaired on the spot in repair station. The second part of the report is the FILE STATISTICS. The SERVICE ACTIVITY STATISTICS show that the four service activities modeled as activities 31, 32, 33 and 34 (Figure 4) are highly utilized (e.g. more than $95 \%$ of the time) [6]. The inspection activities are 31,32 and 33, while activity 34 is the repair phase when a vehicle fails the test. 


\section{Simulation Results}

The model performance is evaluated according to the scenarios as shown in Table 1 . The simulation model is run 14 times and the results are shown in Table 2(a). The average system time in registration and inspection center is approximately 83 minutes. The standard deviation is about 51, which suggests that some vehicles need longer times for repair. The number of observations in the simulation study is about 2530 cars for a period of 6000 minutes. The frequency distribution of the system time is an exponential distribution, with a mean of 83 minutes. The maximum and minimum system times are 519 and 31 minutes respectively. The average waiting time in Queues 3, 4, 5 and 6 are shown in Table 2(b). The average waiting time in Queue 3 is about 15 minutes, while in Queues 4 and 5, the waiting time is 5.4 and 1.55 minutes. The cars enter the QUEUE node based on the smallest size in queue rule with a SELECT node in a BLOCK mode and is used when the queues are in full capacity. The car is forced to enter the queue.

\begin{tabular}{|c|c|c|c|}
\hline & Sechario A & Sevnarie B & Scenario $\mathrm{C}$ \\
\hline Evaluate the Performances in Categary & Non of servers & Ne. of servers & Now of servers \\
\hline A verage wait time for Queue 3, 4, 5 and 6 & 3 & 4 & 5 \\
\hline Average utilization for activity $\# 31,32,33$ and 34 & 3 & 4 & 5 \\
\hline Maximum idle time for activity $\# 31,32,33$ and 34 & 3 & 4 & 5 \\
\hline Maximam busy time for activity $\$ 31,32,33$ and 34 & 3 & 4 & 5 \\
\hline
\end{tabular}

Table 1: Scenario Analysis

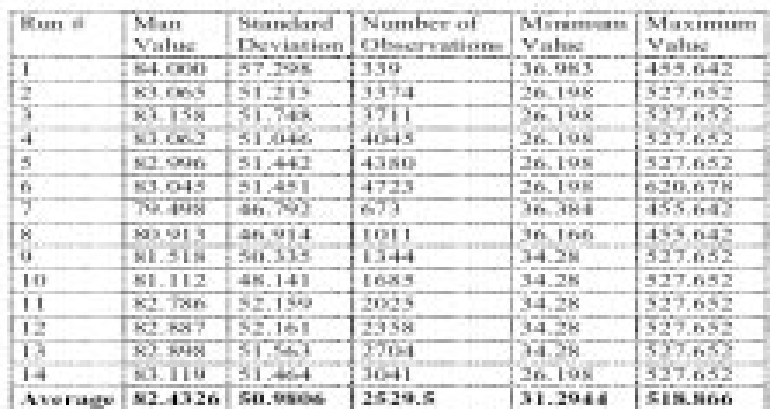

Telte 2 ial System Teme

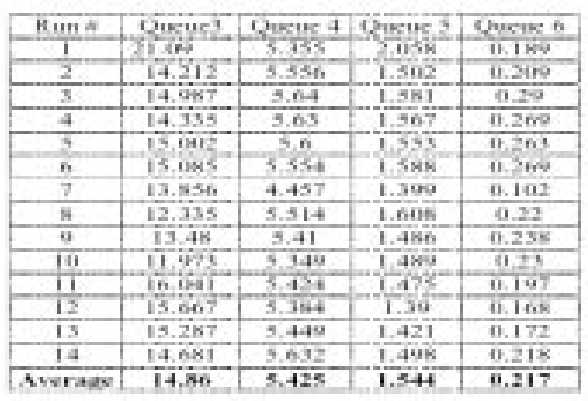

Table 21ti: Averege waiting Time (Queuc ares!

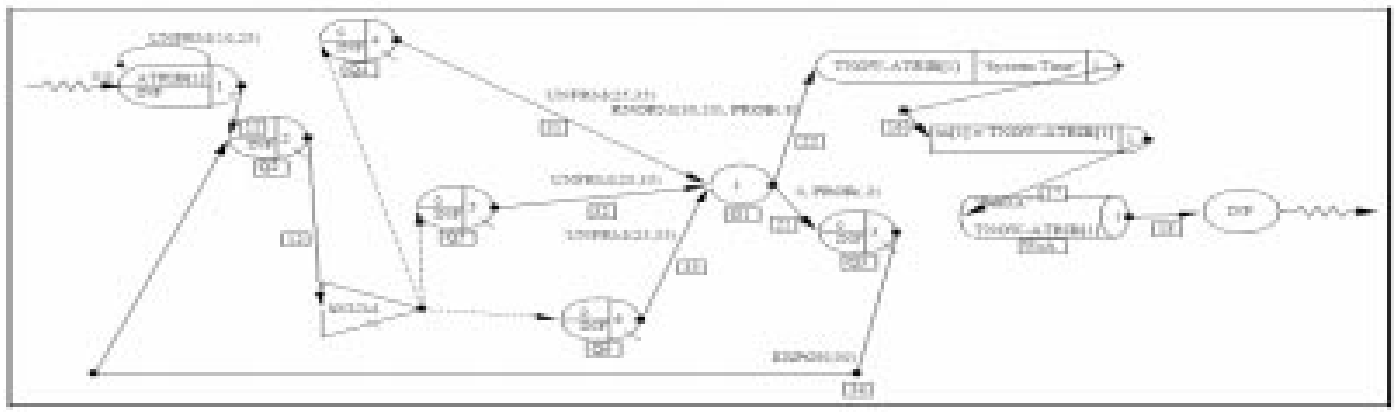

Figure 4: Visual SLAM network of car inspection

\section{DECISION SUPPORT SYSTEM (DSS)}

The simulation results show variability; hence, the decisions based on a single set of output is not reliable. To reduce variance in the simulation study, various replications of the study are generated. The DSS analysis with experimental design is a meta-model [9] and is convenient to 
interpret the results $[10,11]$. In DSS the factors of exogenous and endogenous variables are calibrated for sensitivity analysis $[12,13]$. The DSS also optimizes the system response $[14,10]$. For a small number of input variables, a $3 \mathrm{k}$ factorial design is preferred. In full factorial design, the number of design points is large for a large number of input. A response surface with a small design, the meta-model requires $2 \mathrm{k}$ fractional factorial design [15, 16 and 17]. The Plackett and Burmann [18] fractional factorial design investigates many factors simultaneously without having to investigate all the possible combinations of factors [19]. This design is not widely used in simulation. Multiple replications of simulation results constitute framework to design metamodel. The small designs require less number of simulation runs to model a DSS for performance evaluation [20]. The DSS model incorporates investigative and projection capabilities. The proposed DSS has the following steps:

a.) A design of experiment model with simulated data determines the model parameters

b.) Statistical analysis of the model and model parameters supports the DSS

c.) The simulation is validated with statistical analysis

d.) Cause effect analysis is provided for predictive purpose.

The statistical tests include $\mathrm{R}^{2}$, Sum of Square Error, mean absolute error, Mean Percentage Error and probability test. The average waiting time, is an indication of the system response time. The system time is a system variable. It is the combination of the waiting time and service time. The service time is server related and is a technological factor. If service is considered constant with some parameter, then the system time is directly proportional to the waiting time. Hence, the waiting is an indication of the system time. The DSS model is expressed as

$$
y=a_{1} x_{1}+a_{2} x_{2}+a_{3} x_{3}+\varepsilon
$$

where

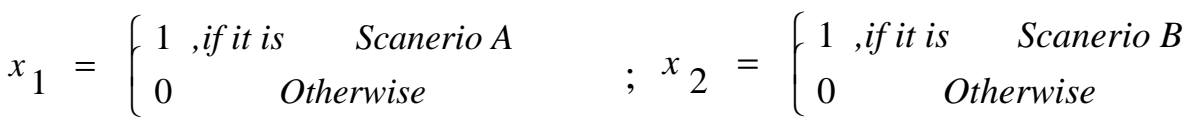

$$
\begin{aligned}
& x_{3}=\left\{\begin{array}{l}
1 \text {, if it is } \quad \text { Scanerio } C \\
0 \quad \text { Otherwise }
\end{array} ; \text { and } \varepsilon=\right.\text { Error term }
\end{aligned}
$$

Next, the null hypothesis that the mean waiting times in the system are equal is tested

$$
\mathrm{H}_{0}: \mathrm{a}_{1}=\mathrm{a}_{2}=\mathrm{a}_{3}
$$

against the hypothesis that at least one mean of the proposed scenario is different

$$
\mathrm{H}_{0}: \mathrm{a}_{1} \neq \mathrm{a}_{2} \neq \mathrm{a}_{3}
$$

In Tables 4 and 5, it is evident that the computed value of $F$ exceeds the critical value; hence the null hypothesis $\mathrm{H}_{0}: \mathrm{a}_{1}=\mathrm{a}_{2}=\mathrm{a}_{3}$ is rejected and we conclude that the proposed scenarios have different mean waiting times. This implies that resources influence service factors. In order to test the validity of the DSS, we tested the flowing hypotheses: $\mathrm{H}_{01}: \mathrm{a}_{1}=0 ; \mathrm{H}_{02}: \mathrm{a}_{2}=0 ; \mathrm{H}_{03}: \mathrm{a}_{3}=0$ against $\mathrm{H}_{11}: \mathrm{a}_{1} \neq 0, \mathrm{H}_{12}: \mathrm{a}_{2} \neq 0$ and $\mathrm{H}_{13}: \mathrm{a}_{3} \neq 0$. Since the $\mathrm{p}$-values are almost negligible, we rejected $\mathrm{H}_{01}: \mathrm{a}_{1}=0, \mathrm{H}_{02}: \mathrm{a}_{2}=0$, and $\mathrm{H}_{03}: \mathrm{a}_{3}=0$ and concluded that the regressors in the proposed DSS contributed significantly. Hence some degree of delay in car registration is expected. Also, the correlation coefficient is significant and explains about the $85 \%$ of the variances, while the $\mathrm{F}$ value is also significant at 41.5. It is clear that the system time significantly reduced the waiting time from 51.33 minutes in scenario A to 12.67 minutes in scenario $\mathrm{B}$, while with scenario $\mathrm{C}$ it 
was 5.81 minutes. The results in Tables 3 and 4 show that the model is statistically significant. The ANOVA in Table 4 does not detect statistically significant lack-of-fit. Moreover, the overall $\mathrm{F}$ test is significant and leads to the acceptance of the proposed DSS meta-model.

The average waiting time for service, average utilization of the facilities, and maximum idle and busy time of the facilities are collected from the simulation summary report. The length of the waiting line and average waiting time are one of the indexes to measure the service performance. The sensitivity analysis provided relevant information for queue length in relation to the number of employees. Figures 5, 6, 7 and 8 display the scenarios information of the service system. From Figure 5, it is evident that by increasing the number of employees, the customer waiting time is improved for Queues 1, 2, 3 and 4. The utilization of the employees also improved, but for Queue 4, no significant improvement was recorded (Figure 6). Further, the idle time (Figure 7) was improved with the variations of employees. Figure 7 suggests that Scenario 2 is suitable, since the idle time is minimized compared to other alternatives.
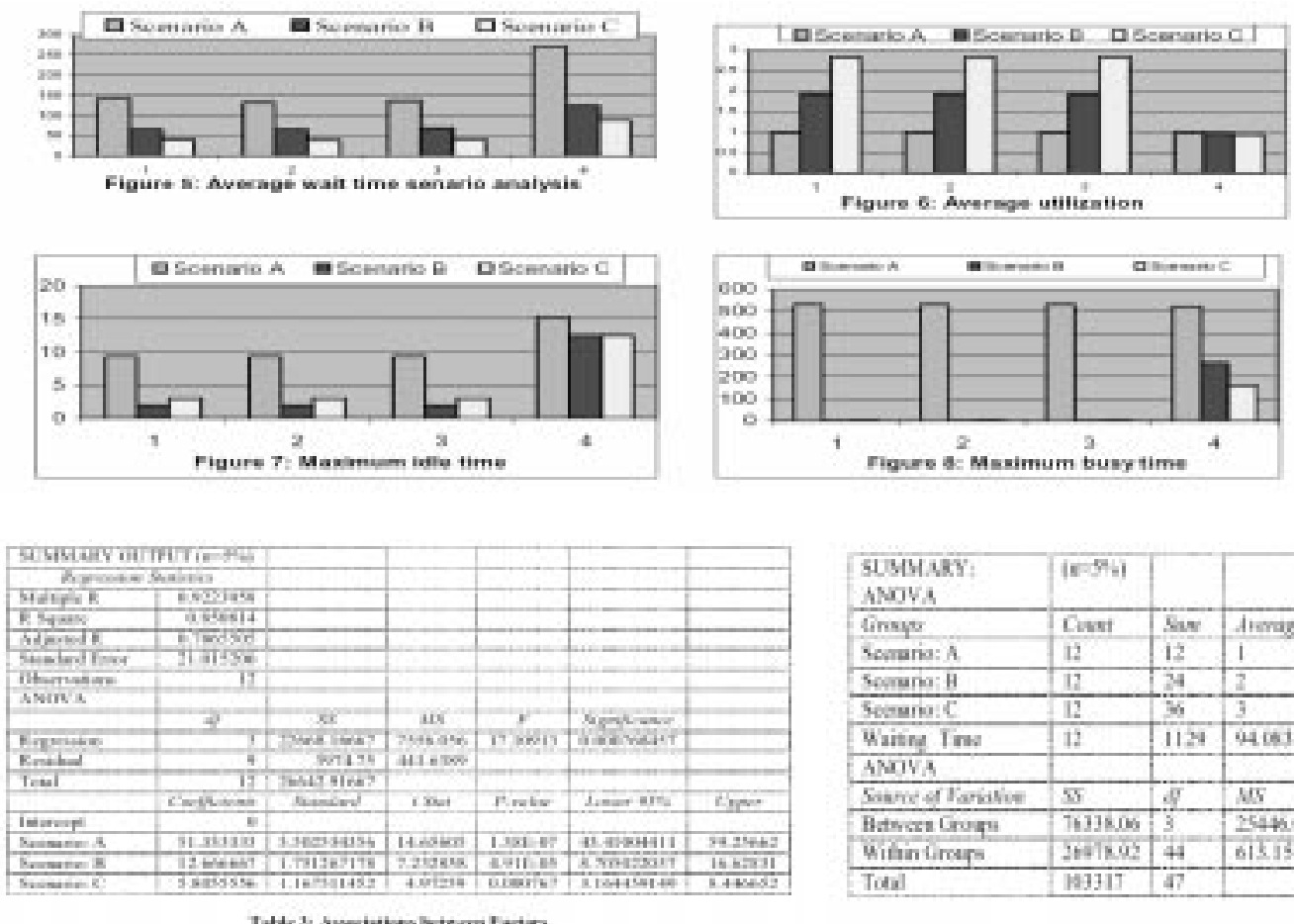

\begin{tabular}{|c|c|c|c|c|c|c|}
\hline $\begin{array}{l}\text { SUMMAKY: } \\
\text { ANOVA }\end{array}$ & (E-5) & & & & & \\
\hline Cinsuyo & Covet & Siv & dienage & Forianx & & \\
\hline Sonaria: A & 12 & 12 & 1 & $2.1 \times 1 \times 18$ & & \\
\hline Sequina: $\mathrm{H}$ & 12 & 3 & 2 & 5.727273 & & \\
\hline Sestram:C & 12 & $\$$ & 3 & 1463626 & & \\
\hline Waitry Irea & 12 & 1124 & 946533 & 2422106 & & \\
\hline \multicolumn{7}{|l|}{ AMVA } \\
\hline Sinere f Tonisive & 55 & 4 & MS & $F$ & P.nowe & Fov \\
\hline Batsere Grug" & 7633606 & 3 & $24 k=2$ & 415 & 6.ME. 13 & 2816464 \\
\hline Wian Limers: & $2601 \times 02$ & +4 & $61513 \% 2$ & & & \\
\hline Tonal & 153317 & 47 & & & & \\
\hline
\end{tabular}

Takb \& ANo A betvese Fiaters

\section{CONCLUSIONS}

From a simulation analysis a DSS model was developed for the car registration and renewal operation. The simulation analysis identified the inspection area as the bottleneck in the system. The DSS meta-model provides sensitivity analysis and evaluates the service industry performance. The model parameters help a manager to interpret decisions without the help of an expert. As the services of car registration and renewal are subcontracted to different agencies over the years, the analysis helps in proving reliable estimates of the costing and stuffing requirements. The simulation and DSS analysis measures the performance of the systems relative to the customer satisfaction. Also the analysis identifies the consequences of the resources as shown in the scenario analysis. The length of waiting time is high and hence such 
circumstances indicate loss of productivity in the business. This scenario analysis illustrates how to improve the expected time required to finish the car registration and renewal.

\section{REFERENCES}

1. Pritsker, A.A. B., O’Reilly, J.J. (1999). Simulation with Visual SLAM. JW, NY, USA.

2. Valdivia M.T. R and Cowe T.J. (1997). Achieving Hospital Operating Objectives in the Light of Patient Performances, Int. Journal of health Care Quality Assurance, 10(5), 208-212.

3. Evans J. R. \& Olson, D.L., (2002). Introduction to Simulation and Risk Analysis, $2^{\text {nd }}$ Ed. PH,NJ, USA.

4. Lopez-Valcarcel, B.G \& Perez, P. B. (1994). Evaluation of Alternative Functional Designs in an Emergency Department by Means of Simulation. Simulation, 63(1), 20-28.

5. Clark Jr. T.D., Hammond, D.H. \& Cossick, K. L. (1992). Management Policies to Improve the Effectiveness of Multistation Service Organizations, Decision Science, $\underline{3}$, 1099-1022.

6. Harrell, C., Tumay. K. (1995). Simulation Made Easy A Manager's Guide, Engineering \& Management Press, 25 Technology Park, Norcross, Georgia, USA.

7. Kelton W. D., Sadowski, R. P. \& Sadowski D.A. (2002). Simulation with ARENA, McGraw Hill, NY, USA.

8. Fardane, T., Obaidly, M. (2002). Renewal \& Registration in Traffic Department, Report, UAEU.

9. Friedman, L.W. (1996). The Simulation Metamodel, Kluwer Academic Pub., Norwell, MA.

10. Shang,J.S. \& Tadikamalla, P.R., (1998). Multicriteria design and control of cellular manufacturing system through simulation \& optimization, IJPR, 36(6),1515-1528.

11. Hurrion, R.D. \& Birgul, S., (1999). A comparison of factorial \& random experimental design methods for the development of regression \& neural network simulation metamodels, $\underline{J}$. of the Operational Research Society, 50(10), 1018-1033.

12. Kleijnen, J.P.C. (1977). Searching for important factors in simulation models with many factors: Sequential bifurcation, EJOR, $\underline{96}$ (1), 180-194.

13. Hunter, J.S., \& Naylor, T. H. (1970). Experimental designs for computer simulation experiments, Management Science, 16(7), 422-434.

14. Madu, C.N. \& Kuei, C.H. (1992). Group screening and taguchi design in the optimization of multi-echelon maintenance .oat simulation metamodels, Comp. \& O.R, 19 (2), 95-105.

15. Box, G.E.P., Hunter, J.S. (1961). The 2k_p factorial designs, Technometrics 3, 311-351.

16. Hood, S.J. and Welch, P. D. (1993). Response surface methodology and its applications in simulation, Proceedings of Winter Simulation Conference, 115-122.

17. Inci, B. \& Semra, T. (2003). Small response surface designs for metamodel estimation, European Journal of Operational Research, 145, 455-470.

18. Plackett, R.L. \& Burman, J.P (1946). The design of optimum multifactorial experiments. Biometrica, 33, 305-325.

19. Durig, T. \& Fassihi, A. R. (1993). Identification of stabilizing and destabilizing effects of experiment-drug interactions in solid dosage from design. Int. J. of Pharmaceutics, 97, 161-170.

20. John, R.C. \& Draper, N.R. (1975). D-optimality for regression designs: A review, $\underline{\text { Technometrics, }}, \underline{17}, 5-23$. 